\title{
Exploration of Dancun-Longyang town fault at the site about project of LNG peak shaving station and gas supply pipeline in Luyang Lake
}

\author{
Fengwen Ren ${ }^{1}$, Baolai $\mathrm{Li}^{1}$, Dangming Chen ${ }^{1}$, Chunfeng $\mathrm{Li}^{1 *}$ and Weixin $\operatorname{Tian}^{1}$ \\ ${ }^{1}$ Shaanxi Earthquake Agency, Xi'an, Province, 710086, China
}

\begin{abstract}
In this paper, the method of combining high-density electrical exploration and borehole joint profile is used to explore the Dancun-Longyang town fault at the LNG peak shaving station and gas supply pipeline engineering site of Luyang lake. The distribution and activity of the fault are determined, providing a basis for seismic fortification and seismic geological disaster evaluation in the line
\end{abstract}

\section{Introduction}

In general, Dancun-Longyang town fault is a part of the Fufeng-Liquan-Fuping fault, which has a certain control effect on the formation and Cenozoic sedimentation of Weihe basin (Xu Yujian, 1988; Deng Qidong, 1999; Tian Qinjian, 2003; Ren Jun, 2013, etc.). The fault is characterized by a set of Liangwa landform features with fault uplift and fault depression alternately distributed.

The project of "Seismic Microzonation of Weinan City" (Shaanxi Engineering Seismic Survey and Research Institute, 2011) and "Seismic Microzonation of Xianyang City" (Shaanxi Engineering Seismic Survey and Research Institute, 2011), and other projects have done a lot of work on the Dancun-Longyang town fault. According to the analysis of previous data, the Dancun-Longyang town fault is distributed in the slope area on the south side of Luyang lake and intersects with the proposed gas supply pipeline. However, the specific distribution and activity of the fault in the engineering site are not clear. Therefore, in this paper a combination of high-density electrical method exploration and borehole joint profile is used to conduct a detailed exploration of the Dancun-Longyang town fault in the site, to accurately determine the intersection of the fault and the gas supply pipeline, and to provide a basis for the engineering seismic work of the site.

\section{Project overview and distribution of active faults in the project site}

The LNG peak shaving station of Luyang lake is located in the southeast corner of modern industrial comprehensive development zone, with an area of 154.65 mu. The gas supply pipeline is laid to the northeast after leaving the station from the Luyang lake off load station, passing through $\mathrm{x} 313$ county road and the second branch of Luohui west trunk canal, and then to LNG peak shaving station through Beizhang village, with a total length of about 8.8 kilometers (Figure 1). It is a major lifeline project with large investment and high safety requirements.

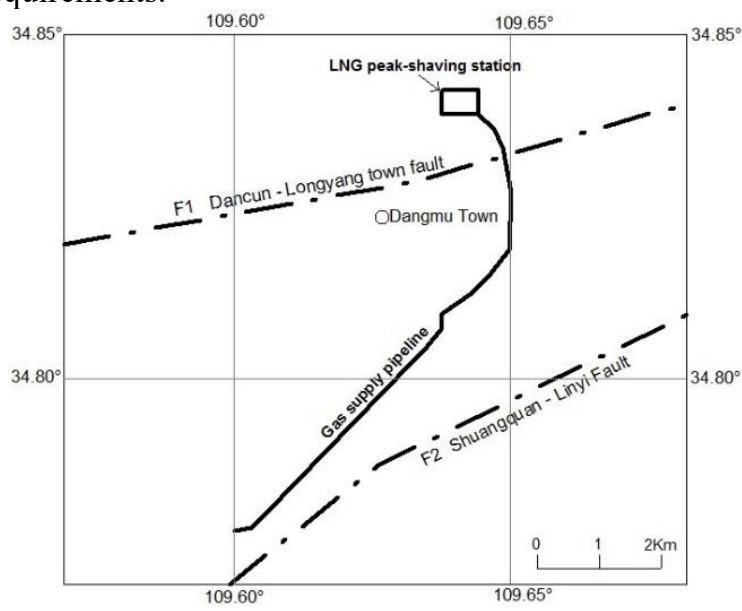

Figure 1. Main active faults in the engineering site

Figure 1 shows the distribution of major active faults in the LNG peak shaving station and gas supply pipeline engineering site of Luyang lake. It can be seen from Figure 1 that the main active faults in the site are the Dancun-Longyang town fault and the Shuangquan-Linyi fault. Because the Dancun-Longyang town fault crosses the gas pipeline, this paper mainly studies the exploration of the fault.

\section{Survey of Dancun-Longyang town fault}

It can be seen from Figure 1 that Dancun-Longyang town 
fault intersects with the proposed gas supply pipeline. Therefore, high-density electrical exploration and borehole exploration are deployed nearby the site area. The survey work layout and fault distribution are shown in Figure 2.

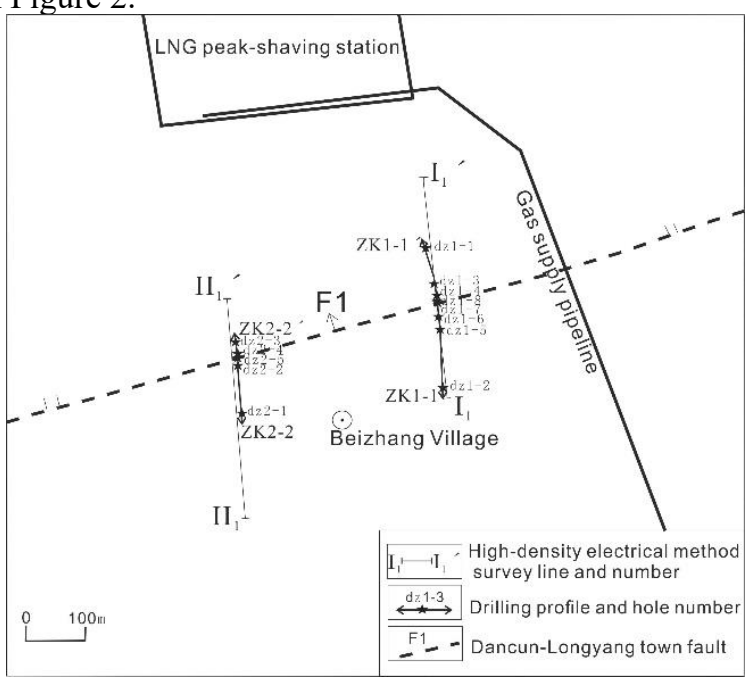

Figure 2 The survey work layout and fault distribution

On the basis of considering the overall strike and site conditions of Dancun-Longyang town fault, at the south slope of the site, two high-density electrical survey lines and two borehole exploration sections are arranged in a north-south direction (Fig. 2). Among them, a high-density electrical survey line $\left(\mathrm{I}_{1}-\mathrm{I}_{1}{ }^{\prime}\right)$ and a borehole profile (ZK1-1') are set in the east of Beizhang village, with the length of $378 \mathrm{~m}$ and $254 \mathrm{~m}$ respectively; a high-density electrical survey line $\left(\mathrm{II}_{1}-\mathrm{II}_{1}{ }^{\prime}\right)$ and a borehole profile (ZK2-2') are set in the west of Beizhang village, with the length of $378 \mathrm{~m}$ and $116 \mathrm{~m}$ respectively.

\subsection{High-density electrical exploration and its results}

In this work, the high-density electrical prospecting was firstly carried out, and two high-density electrical survey lines were arranged to determine the specific location of the intersection of the Dancun-Longyang town fault and the proposed gas pipeline. The distance between measuring points of the survey line is $6 \mathrm{~m}$, and the arrangement length is 64 points.

WGMD-9 ultra-high density resistivity test system was used to test the data in the field. After data conversion and error correction, etc. The 2D high-density inversion processing software $2 \mathrm{DERS}$, which is provided by Chongqing benteng $\mathrm{CNC}$ geophysical exploration instrument research and development center, is used to manually set various inversion parameters in advance. The resistivity data are inversed by using the least square method, and then the profile resistivity cross-section is obtained.

$\mathrm{I}_{1}-\mathrm{I}_{1}{ }^{\prime}$ is the high-density electrical survey line section in the east of Beizhang Village (Fig. 2). The $\rho$ s contour profile and image analysis of the survey line $\mathrm{I}_{1}-\mathrm{I}_{1}{ }^{\prime}$ is shown in Fig.3(a). From the analysis of the image chart, the apparent resistivity changes on both sides of the survey line are relatively uniform. There is an obvious northward dipping high resistivity zone near the survey line $150 \mathrm{~m}$, which is supposed to be caused by faults. The plane projection position of electrical anomaly point is shown in Fig. 3 (a).

$\mathrm{II}_{1}-\mathrm{II}_{1}{ }^{\prime}$ is the high-density electrical survey line section in the west of Beizhang Village (Fig. 2). The $\rho s$ contour profile and image analysis of the survey line $\mathrm{II}_{1}-\mathrm{II}_{1}{ }^{\prime}$ is shown in Fig.3(b). From the analysis of the image chart, the apparent resistivity changes from south to North in the profile of the survey line as a whole is relatively uniform. There is only a high resistivity abnormal surface near the survey line $220 \mathrm{~m}$, which inclines to $\mathrm{N}$, which is supposed to be caused by faults. The plane projection position of electrical anomaly point is shown in Fig. 3 (b).

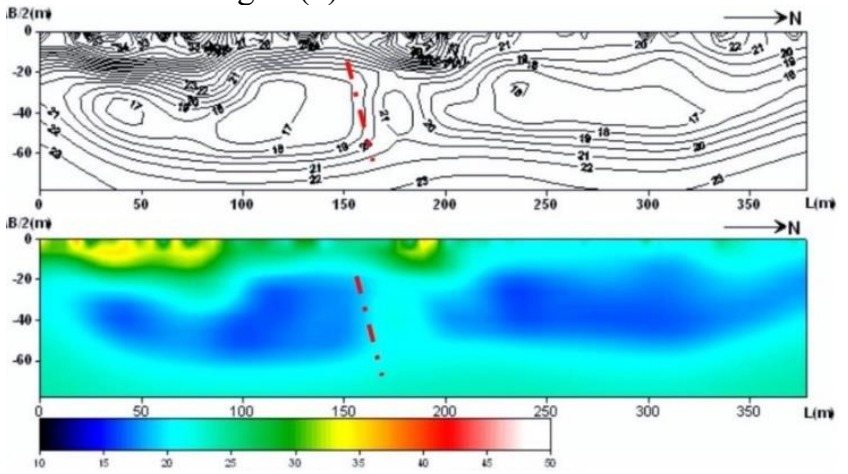

(a)

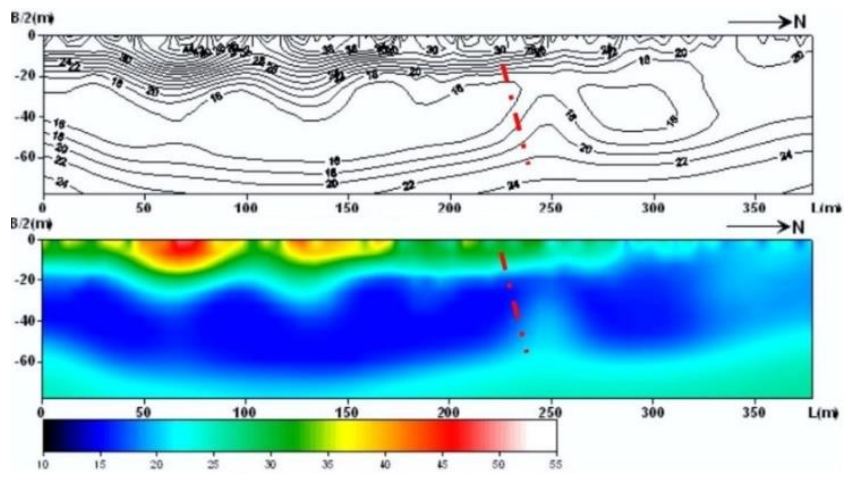

(b)

Figure 3 Interpretation of high-density electrical exploration

\subsection{Drilling exploration and its results}

In order to further verify the test results of high-density electrical method, a drilling exploration section is arranged at the position where it coincides with the high-density electrical survey line. Eight boreholes have been drilled in the ZK1-1 ' drilling exploration profile in the east of Beizhang village, with the single hole depth controlled at about $50 \mathrm{~m}$, the maximum hole spacing of $101 \mathrm{~m}$ and the minimum hole spacing of $7.5 \mathrm{~m}$ (Fig. 4). Five boreholes have been drilled in the ZK2-2 ' drilling exploration profile in the west of Beizhang village, with the single hole depth controlled at $50 \mathrm{~m}$, the maximum hole spacing of $82 \mathrm{~m}$ and the minimum hole spacing of 8.5m (Fig. 5).

ZK1-1' drilling exploration profile (Fig. 4) shows that obvious vertical dislocation of strata occurs between the boreholes dz1-7 and dz1-8, which is speculated to be caused by the activity of the Dancun-Longyang town fault. The fault dips northward, the south side rises and 
the north side descends. The bottom boundary of the late Pleistocene ancient soil layer is vertically offset by about $10 \mathrm{~m}$.

ZK2-2' drilling exploration profile (Fig. 5) shows that obvious vertical dislocation of strata occurs between the boreholes dz2-2 and dz2-4, which is speculated to be caused by the activity of the Dancun-Longyang town fault. The fault dips northward, the south side rises and the north side descends. The bottom boundary of the late Pleistocene ancient soil layer is vertically offset by about

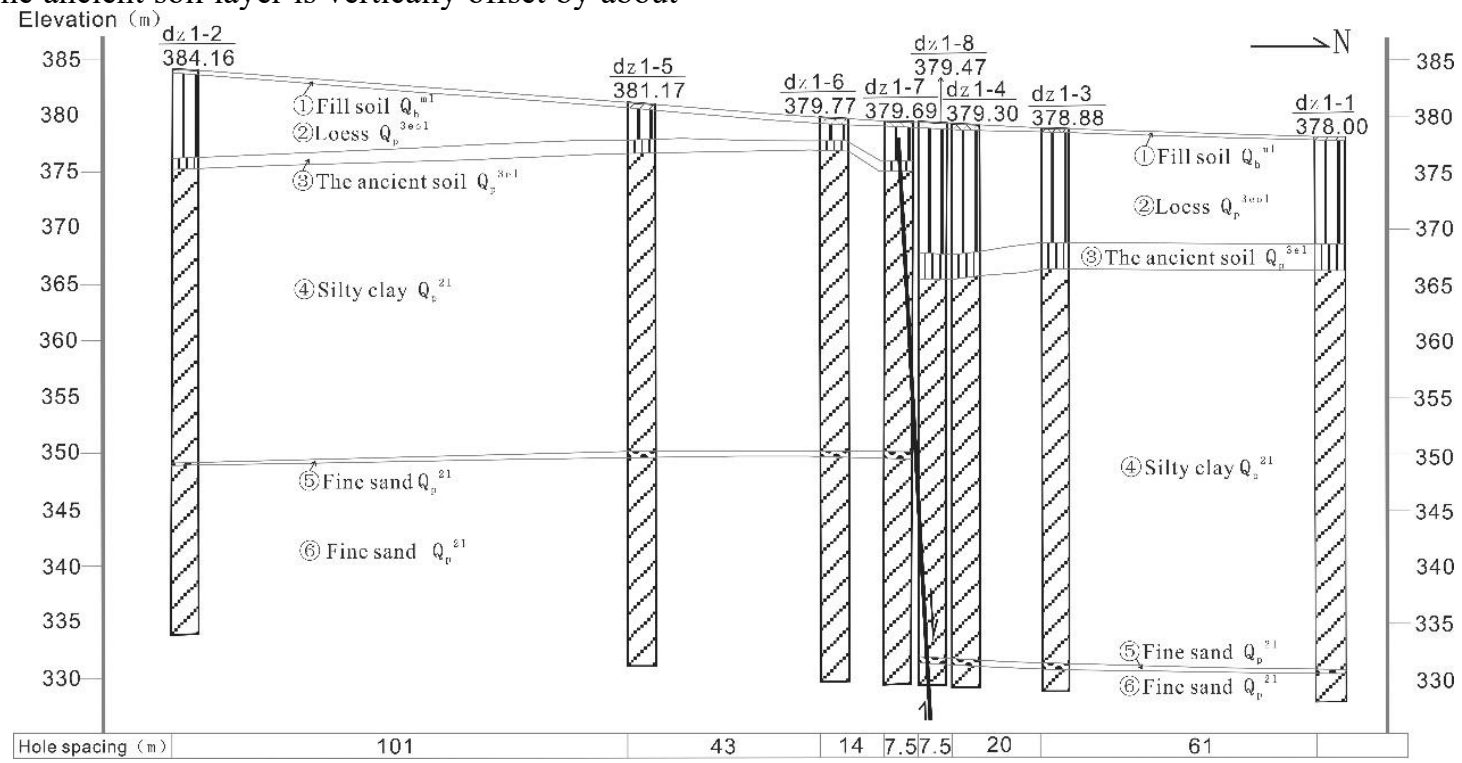

Figure 4 ZK1-1' drilling exploration profile

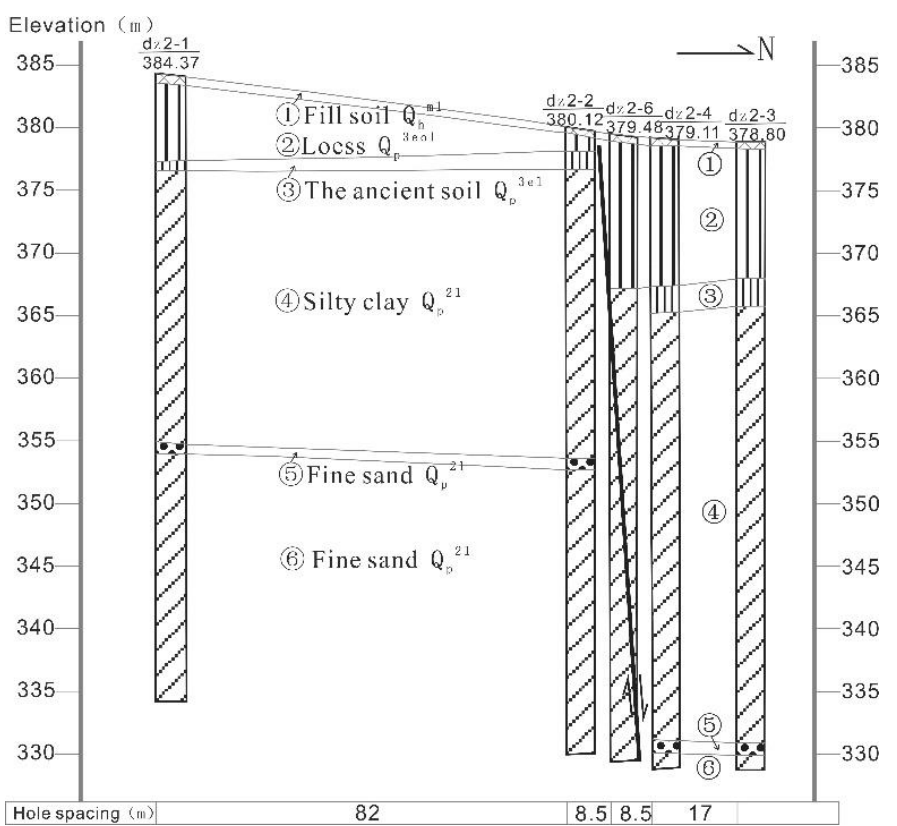

Figure 5 ZK2-2 ' drilling exploration profile

\section{Conclusion}

Both the high-density electrical exploration and drilling exploration reflect the Dancun-Longyang town fault crosses the gas pipeline, and the latest active age of the fault is late Pleistocene. Considering the survey accuracy and referring to the results of other survey points of the fault, the width of fault zone is considered as $30 \mathrm{~m}$. There is no fault passing through the LNG peak shaving station.
$10 \mathrm{~m}$.

The results of borehole exploration show that the Dancun-Longyang town fault does exist, and its plane position is consistent with the result of electrical prospecting. The fault dislocates the late Pleistocene ancient soil layer (S1) with a vertical offset of $10-12 \mathrm{~m}$ at the bottom (Fig. 4 and Fig. 5), belonging to the active fault since the late Pleistocene. 


\section{References:}

1. Deng, Q.D., Cheng, S.P., et al. (1999) Discussion on Cenozoic tectonics and dynamics of Ordos block .J. Journal of Geomechanics, 5(3):13-20.

2. Ren, J., Feng, X.J., et al. (2013) Revealed the fine crust structures of Xi'an sag in Weihe basin by deep seismic reflection profile. J. Chinese Journal of Geophysics, 56(2):513-521.

3. Xu, Y.J., Shen-tu, B.M., et al. (1988) A preliminary study of the characteristics of the activity of the northern boundary fault belt of Weihe basin. J. Seismology and Geology, 10(4):77-87.

4. Tian, Q.J., Shen, X.H., et al. (2003) Primary study on quaternary tectonic events based on variation of fault activity in Weihe basin. J. Seismology and Geology, 25(1):146-154.

5. Shaanxi Engineering Seismic Survey and Research Institute. (2011) Work report of seismic microzonation in Weinan City.

6. Shaanxi Engineering Seismic Survey and Research Institute. (2011) Work report of seismic microzonation in Xianyang City. 